\title{
Surfactant-Mediated Solubilization of Magnetically Separable Nanocatalysts for the Oxidation of Alcohols
}

\author{
Aratrika Chakraborty, ${ }^{\dagger}$ Tonmoy Chakraborty, ${ }^{\dagger}$ Maria Isabel Menendez, ${ }^{*} \neq \odot$ \\ and Tanmay Chattopadhyay*, $\$$ \\ ${ }^{\dagger}$ Department of Chemistry, University of Calcutta, 92, A. P. C. Road, Kolkata 700009, India \\ ${ }^{*}$ Departamento de Química Física y Analítica, Universidad de Oviedo, C/ Julián Clavería 8, 33006 Oviedo, Spain \\ ${ }^{\S}$ Department of Chemistry, Diamond Harbour Women’s University, Diamond Harbour Road, Sarisha, South 24 Pgs (S) 743368, \\ India
}

Supporting Information

ABSTRACT: Cetrimonium bromide (CTAB)-coated water disperse magnetically separable nanocatalysts $\mathrm{CTAB} / \mathrm{Fe}_{3} \mathrm{O}_{4} @$ dopa@ML $(\mathrm{M}=\mathrm{Fe}$ or $\mathrm{Mn}, \mathrm{L}=$ cyclohexane-1,2-diylbis(azanylylidene)bis(methanylylidene)bis(2,4-diXphenol; $\mathrm{X}=\mathrm{Cl}, \mathrm{Br}$, and $\mathrm{I}$ ) have been synthesized using a simple synthetic strategy. This approach provides a new fruitful strategy to reduce the leaching of the active metal complex from the catalyst surface to the aqueous media. The synthesized catalysts have been found to be excellent for oxidation of alcohols in aqueous medium at room temperature. A probable catalytic pathway involving the generation of hydroperoxo intermediates has been assumed, and these intermediates have been characterized using density functional theory and several spectroscopic techniques. It is worthy of mention that the synthesized CTAB-coated magnetically separable nanocatalysts can be magnetically recovered from the aqueous reaction mixture after more than five cycles, which renders this approach as a sustainable and accessible one.

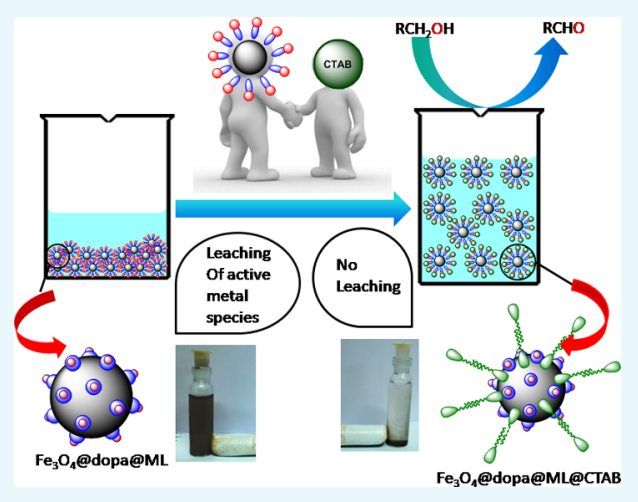

\section{INTRODUCTION}

Cleaner and greener protocols coupled with safe and mild conditions for oxidation of alcohols are high in demand in modern organic chemistry because the oxidation products are the foundation of various natural, unnatural, and biologically active molecules. ${ }^{1-7}$ To date, many reports for the oxidation of alcohols using environmentally toxic metal oxidants or the combination of the oxidant and heavy metal-based catalysts are available. However, most of the catalytic reactions mainly suffer from low cost effectiveness and lack of green and sustainable reaction conditions. ${ }^{8-12}$ Therefore, cheap and eco-friendly reaction procedures for the selective oxidation of alcohols are demanded.

In this context, heterogeneous metal-supported catalysts in an aqueous medium may be one of the desirable solutions, considering the ease of recovery and recyclability. Magnetic nanomaterials have drawn extensive attention in the field of nanomaterials and catalysis owing to their superparamagnetic property. Among the known magnetic materials, catalysis iron oxide-based nanoparticles have harnessed much attention with many attractive features like high surface area, high loading, superior efficiency, high thermal stability, effortless recovery, and a cost-effective nature. ${ }^{13-15}$

However, water solubility of the organic starting materials is the main problem that can be resolved by a new strategy based on the use of surfactants that facilitate the formation of micelles.
They will effectively improve the possibility of contact between the organic starting materials and the catalysts in water. ${ }^{16-18}$

The use of surfactants will solve another critical problem regarding the supported metal nanomaterials, that is, the leaching of the metal complex/metal ions from the nanoparticle surface to the bulk phase, which would render the entire process of heterogenization ineffective. In this sense, Lee and coworkers have recently reported a water soluble catalyst system involving $\mathrm{Rh}$ nanoparticles holding a cetrimonium bromide (CTAB)/ ionic liquid micelle structure which emerged as an efficient catalyst in oxidation of alcohols in water. ${ }^{16}$

In this work, we describe the fabrication and full characterization of water soluble iron(III) and manganese(III) Schiff base and complexes immobilized on dopamine-stabilized $\mathrm{Fe}_{3} \mathrm{O}_{4}$ magnetic nanoparticles bearing a $\mathrm{CTAB}$ micelle structure (CTAB $/ \mathrm{Fe}_{3} \mathrm{O}_{4} @$ dopa@FeL and CTAB $/ \mathrm{Fe}_{3} \mathrm{O}_{4} @$ dopa@MnL) (see Scheme 1). These water soluble nanocatalytic systems affords efficient oxidation of alcohols with the aid of a green oxidant, $\mathrm{H}_{2} \mathrm{O}_{2}$, thereby rendering the present approach a much economical, safer, and environmentally benign option. Apart from improving the reaction conditions, we have assumed that hydroperoxo intermediates have a relevant role in the reaction

Received: April 20, 2019

Accepted: June 21, 2019

Published: July 2, 2019 
Scheme 1. Schematic Representation of the Synthesis of Bilayer CTAB/ $\mathrm{Fe}_{3} \mathrm{O}_{4} @$ dopa@FeL $(\mathrm{CHCAT}-1)$ and CTAB/Fe $3 \mathrm{O}_{4} @$ dopa@MnL (CHCAT-2)

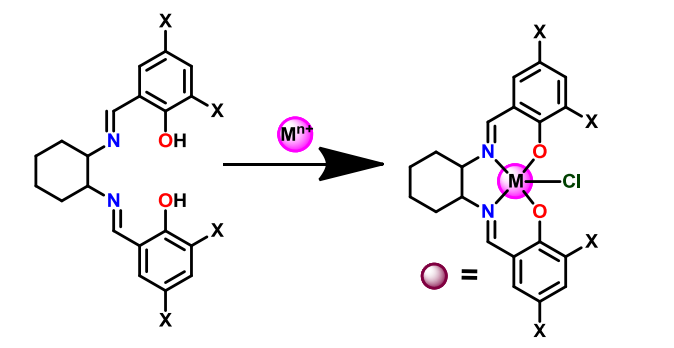

$$
\begin{array}{lll}
-\mathrm{X} & \mathrm{M}^{\mathrm{n}} & \text { Complex } \\
-\mathrm{Cl} & \mathrm{Fe}^{3+} & 1 \\
-\mathrm{Br} & \mathrm{Fe}^{3+} & 2 \\
-\mathrm{H} & \mathrm{Fe}^{3+} & 3 \\
-\mathrm{Cl} & \mathrm{Mn}^{3+} & 4 \\
-\mathrm{Br} & \mathrm{Mn}^{3+} & 5 \\
-\mathrm{I} & \mathrm{Mn}^{3+} & 6
\end{array}
$$
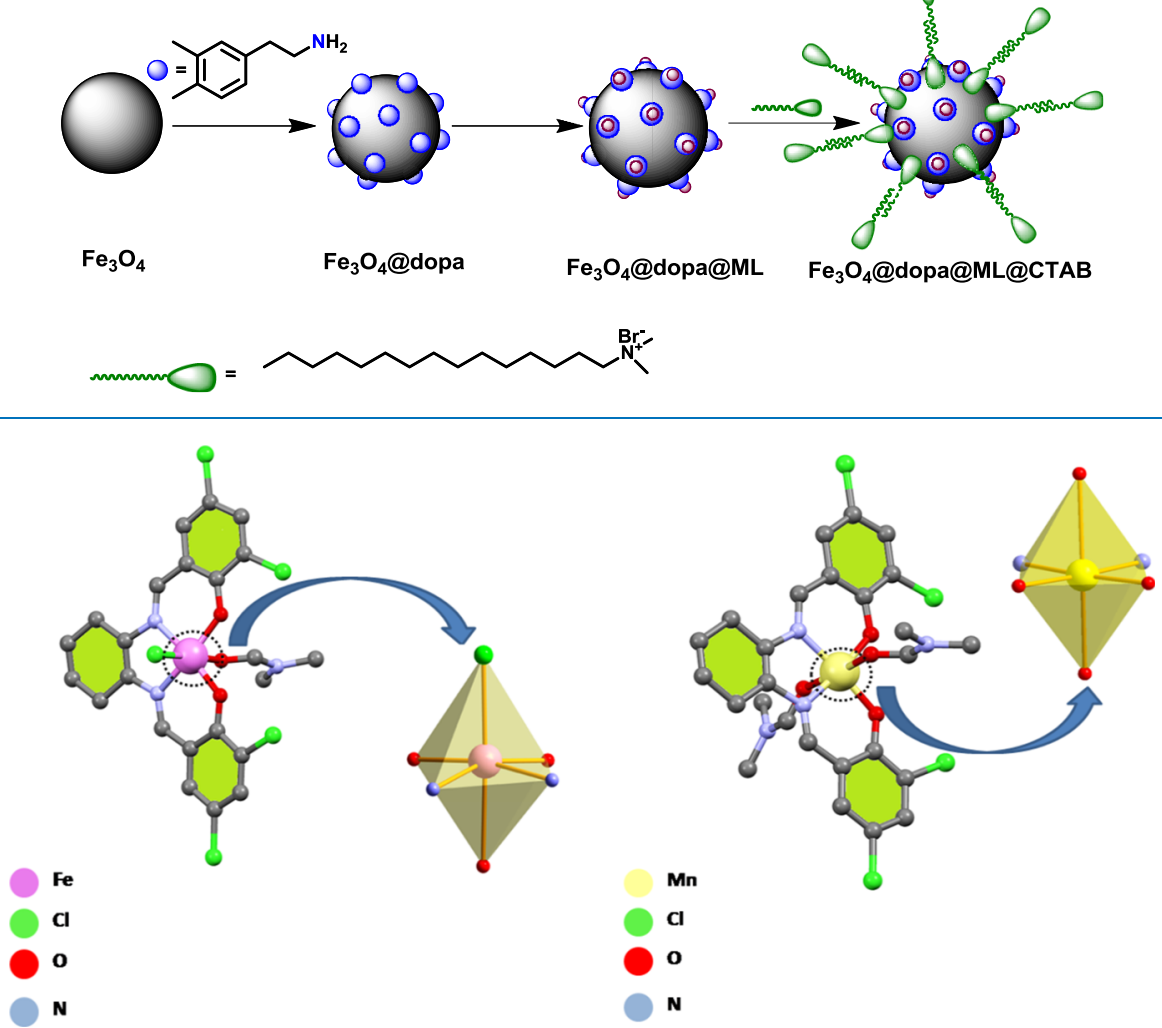

Figure 1. ORTEP drawing (50\% probability ellipsoid) of complex 1 (left) and complex 4 (right).

mechanism and we have characterized them by theoretical calculations based on density functional theory (DFT). The UV-visible and electrospray ionization-mass spectrometry (ESI-MS) studies also support the formation of the hydroperoxo species. To the best of our knowledge, such reports of admicelle formation based on a composite nanoparticle system like the $\mathrm{Fe}_{3} \mathrm{O}_{4} @$ dopa@complex have not yet been reported.

\section{RESULTS AND DISCUSSION}

As a part of our ongoing effort to elucidate the role of the ligand backbone on the oxidation capability of iron and manganese complexes, we synthesized a series of iron(III) complexes namely 1,2 , and 3 , and a series of $\mathrm{Mn}$ (III) complexes namely 4 , 5 , and 6 from a series of tetradentate ligands $\left(\mathrm{H}_{2} \mathrm{~L}^{1}, \mathrm{H}_{2} \mathrm{~L}^{2}, \mathrm{H}_{2} \mathrm{~L}^{3}\right)$ (see Schemes $\mathrm{S} 1$ and $\mathrm{S} 2$ at the Supporting Information). Initially, treatment of $\mathrm{H}_{2} \mathrm{~L}^{1}, \mathrm{H}_{2} \mathrm{~L}^{2}$, and $\mathrm{H}_{2} \mathrm{~L}^{3}$ with $\mathrm{FeCl}_{3} \cdot 6 \mathrm{H}_{2} \mathrm{O}$ forms wine red solutions of $\mathrm{FeL}^{1}, \mathrm{FeL}^{2}$, and $\mathrm{FeL}^{3}$, respectively. Evaporation of the solvent from solutions of $\mathrm{FeL}^{1}$ and $\mathrm{FeL}^{2}$ generated a solid product that rendered dark red crystals of $\mathbf{1}$ and 2 upon recrystallisation from dimethylformamide solution, while treatment of $\mathrm{MnCl}_{2} \cdot 6 \mathrm{H}_{2} \mathrm{O}$ with $\mathrm{H}_{2} \mathrm{~L}^{1}, \mathrm{H}_{2} \mathrm{~L}^{2}$, and $\mathrm{H}_{2} \mathrm{~L}^{3}$ forms deep brown solutions of 4, 5, and 6. Evaporation of the solvent from solutions of $\mathbf{4}$ and $\mathbf{5}$ afforded a deep brown product that yielded deep brown crystals of 4 and 5. Complexes 1, 2 and 4, 5 were characterized by single crystal X-ray diffraction (XRD) analyses (Figure 1). (See Supporting Information for detailed crystal structure elaboration and ORTEP view of complexes 2 and 5, Figure S1 at the Supporting Information). The crystallographic data and details of refinement are given in Table S1 at the Supporting Information, bond length and bond angles for complexes 1, 2, 4, and 5 are given at Tables S2-S5, respectively, at the Supporting Information.

The oxidation of alcohols catalyzed by homogeneous catalysts was initially considered. The catalytic activity of $\mathrm{FeL}^{1}, \mathrm{FeL}^{2}$, $\mathrm{FeL}^{3}, \mathrm{MnL}^{1}, \mathrm{MnL}^{2}$, and $\mathrm{MnL}^{3},(\mathbf{1}-6)$ was studied for alcohol oxidations by $\mathrm{H}_{2} \mathrm{O}_{2}$ (Table $\mathrm{S} 6$ at the Supporting Information). At the onset of the study, benzyl alcohol was selected as the model substrate to determine the optimum reaction conditions such as solvent, amount of oxidant, amount of catalyst, and time. All the reactions were performed at room temperature. Because $\mathrm{H}_{2} \mathrm{O}_{2}$ decomposes rapidly in the presence of iron and manganese catalysts, ${ }^{19}$ we checked that the best way of adding it was drop wise. In the absence of the catalysts, the control reaction gave very poor yield of aldehyde, that is, $<5 \%$ in $4 \mathrm{~h}$, 

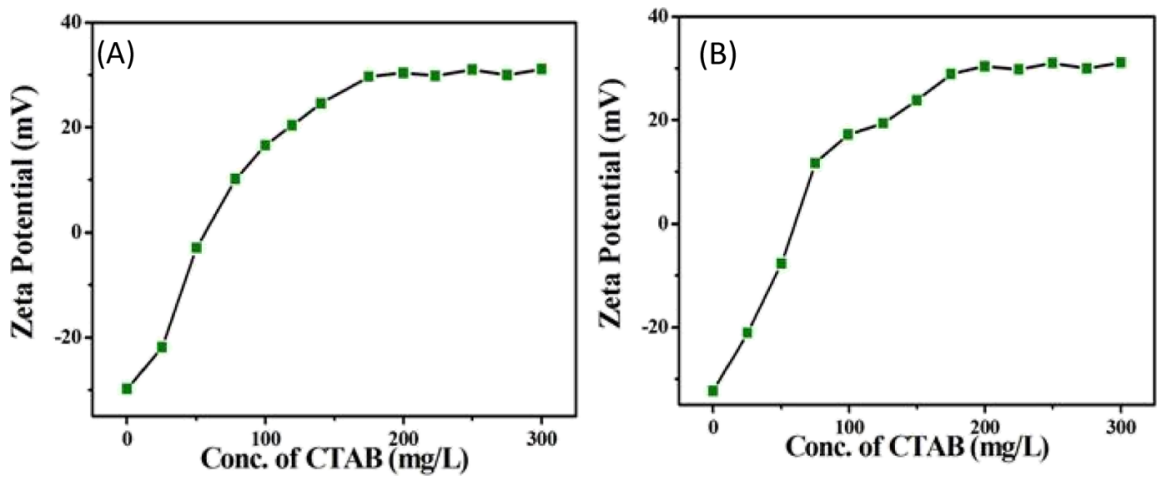

Figure 2. Zeta potential values of (A) CHCAT-1 and (B) CHCAT-2 as a function of concentration of CTAB.
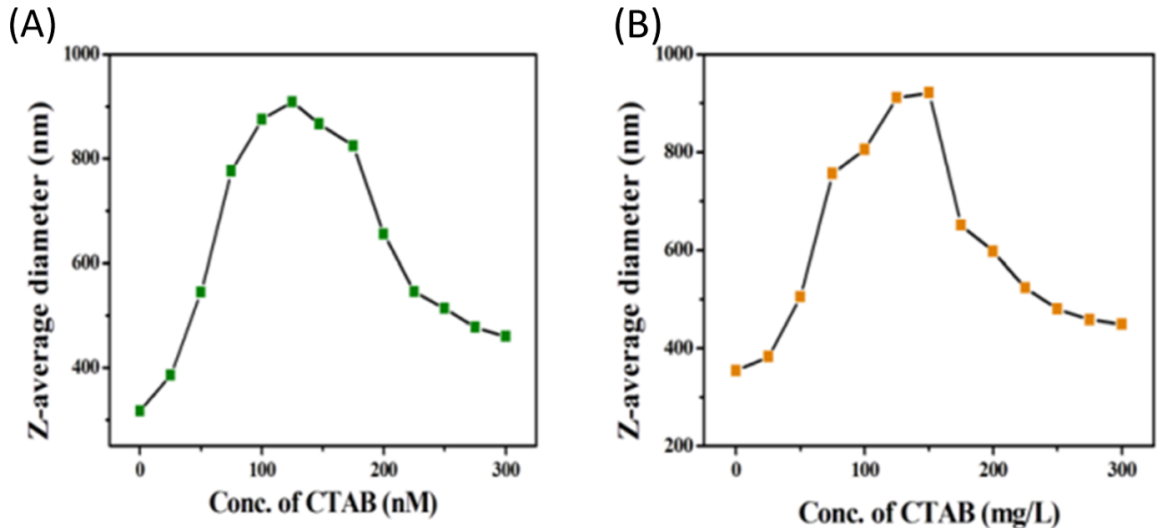

Figure 3. Z-average values of (A) CHCAT-1 and (B) CHCAT-2 as a function of concentration of CTAB.

indicating the crucial role played by catalysts. Oxidation of alcohols using acetonitrile as the solvent gave the best results. To select the optimum catalyst concentration $0.05,0.5,1,1.5,2,2.5$, and $3 \mathrm{mmol}$ of each of the six homogeneous catalysts were used. The reaction completed within $5 \mathrm{~h}$ with a concentration of 0.05 mmol of the catalyst with $80 \%$ conversion and a yield of $55 \%$. The rate of the reaction boosted within $3 \mathrm{~h}$ when the concentration of the catalyst was elevated to $1 \mathrm{mmol}$. The bigger catalyst concentration up to $2 \mathrm{~nm}$ rendered $>95 \%$ yield and $100 \%$ conversion within $4 \mathrm{~h}$. Hence, a catalyst loading of 2 mmol was adjudged to be the optimal one. The role of the concentration of $\mathrm{H}_{2} \mathrm{O}_{2}$ was also investigated. Although slightly lower yields were obtained with a concentration of $0.50 \mathrm{mmol}$ of $\mathrm{H}_{2} \mathrm{O}_{2}$, it rapidly increased when the concentration of $\mathrm{H}_{2} \mathrm{O}_{2}$ was increased to $3 \mathrm{mmol}$. Further reactions were performed with these optimal conditions. All six homogeneous catalysts demonstrated excellent activity for the oxidation of benzyl alcohol (Table S2, entries 1-6). Interestingly, $\mathrm{MnL}^{1}$ and $\mathrm{FeL}^{1}$, with chloro substituents in the catalyst ligand, performed better amongst the six homogeneous catalysts. Therefore, these two homogeneous catalysts were considered for heterogenization with $\mathrm{Fe}_{3} \mathrm{O}_{4} @$ dopa followed by coating with the surfactant.

The zeta potential experiment was performed to investigate the adsorption of surfactants on the nanoparticle surface (Figure 2).At pH7, zeta potential values of $\mathrm{Fe}_{3} \mathrm{O}_{4} @$ dopa@FeL (HCAT1) and $\mathrm{Fe}_{3} \mathrm{O}_{4} @ \mathrm{dopa} @ \mathrm{MnL}$ (HCAT-2) were found to be -31.3 and $-29.8 \mathrm{mV}$, respectively. Considering the surface charge of these nanoparticles, a positively charged surfactant $\mathrm{CTAB}$ has been used for their surface modification. With the increasing concentration of $\mathrm{CTAB}$ the zeta potential value continuously increases, then, reversal of surface charge takes place, and, finally, it becomes almost constant [ 31 and $33.4 \mathrm{mV}$ for CHCAT- 1 and CHCAT-2, respectively (Figure 2)]. The mechanism of adsorption of $\mathrm{CTAB}$ on the nanoparticle surface can be explained considering electrostatic as well as hydrophobic interactions. Initially, the zeta potential value shifted from negative to zero because of formation of hemimicelles, that is, surfactant monolayers, at the cost of electrostatic interaction between the head part of CTAB and the negatively charged surface. Then, mixed hemimicelle formation takes place in the concentration range $20-100 \mathrm{mg} / \mathrm{L}$ due to both the electrostatic and lateral hydrophobic interaction between the tail part of the $\mathrm{CTAB}$ molecules. Finally, at high concentration of the CTAB surfactant, bilayers formed by hydrophobic interactions. Therefore, the surface charge of the admicelles becomes positive.

Figure 3 represents the $Z$-average micelle diameters as a function of CTAB concentrations. At $\mathrm{pH} 7$ the average hydrodynamic radius of the iron and manganese nanoparticles are 347 and $327 \mathrm{~nm}$, respectively. With the increasing concentration of $\mathrm{CTAB}$ the hydrodynamic radii gradually increases up to a certain concentration; then, further increment of CTAB concentration makes it decrease. This phenomenon can be explained in terms of three consecutive processes. At a low concentration range, with the increase of CTAB concentration formation of hemimicelles takes place along with a slight increment of hydrodynamic radii; then, agglomerations takes place among neighboring nanoparticles because of hydrophobic interactions between the tail part of the $\mathrm{CTAB}$ molecules. At a high concentration of $\mathrm{CTAB}$, further agglomerations revert to small nanoparticles.

Figure S2 shows the typical Fourier-transform infrared spectroscopy (FT-IR) spectrum of HCAT-1 and CHCAT-1. 
Prepared nano HCAT-1 shows absorption peaks at around 580 and $631 \mathrm{~cm}^{-1}$, which are the characteristic absorptions of the $\mathrm{Fe}-\mathrm{O}$ bond, confirming the presence of iron oxide, as previously reported. $^{20-23}$ Dopamine incorporation is confirmed by the presence of a peak around $1480 \mathrm{~cm}^{-1}$, which can be attributed to the vibration of the benzene ring present at the dopamine moiety. In the case of CTAB-coated magnetically separable nanoparticle CHCAT-1, a bunch of peaks at 2846, 2914, and $2953 \mathrm{~cm}^{-1}$ can be attributed to the asymmetric and symmetric stretching of $-\mathrm{CH}_{2}$-moieties of the long alkyl chain of CTAB and the antisymmetric stretching mode of the trimethylammonium head group for CTAB are identified by a peak around 3015 $\mathrm{cm}^{-1}$, which further proves the presence of CTAB at the surface of our synthesized magnetically separable nanoparticles CHCAT-1.

The dried powder samples HCAT-1, HCAT-2, CHCAT-1, and CHCAT-2 obtained after washing with the solvent mixtures were characterized by powder XRD (PXRD) for phase purity. The XRD patterns of all four samples confirm the formation of the magnetite phase $\left(\mathrm{Fe}_{3} \mathrm{O}_{4}\right)$, without any other impurities (Figure S3). From the PXRD spectrum of CHCAT-1 in Figure $\mathrm{S} 3$, a peak at $2 \theta=21^{\circ}$ indicates the coating of $\mathrm{CTAB}$ onto the surface of HCAT-1. ${ }^{24}$ Intensities of HCAT-1 are found to be lower than the CHCAT-1 ones, which can be attributed to the alteration in orientation from HCAT-1 to CHCAT-1.

The morphologies of HCAT-1 and its corresponding CTABcoated analogue CHCAT-1 were characterized by scanning electron microscopy technique, which are shown in Figure 4.

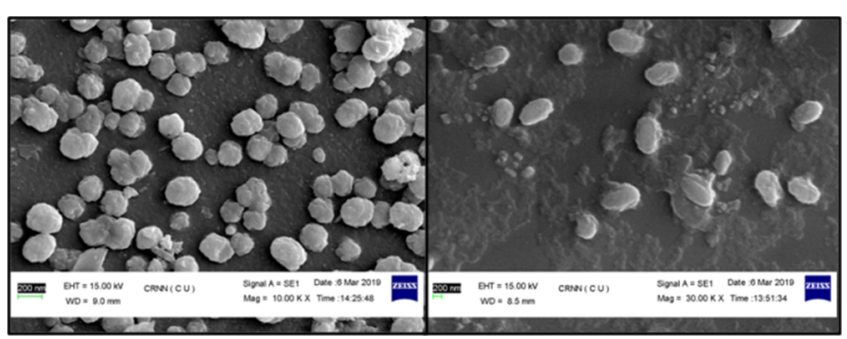

Figure 4. (Left) SEM image of HCAT-1 in the absence of the surfactant CTAB (Right) and SEM image of CHCAT-1.

From Figure 4 (left) it is evident that in the absence of CTAB, roughly spherical particles of HCAT-1 are formed of size ranging from $200-250 \mathrm{~nm}$. In the case of CHCAT-1, roughly oval shaped particles are observed (Figure 4 (right)). In the case of CHCAT-1, the surface is rough as compared to that of HCAT-1, which indicates CTAB-induced surface modification. $^{25,26}$ Similarly, from the scanning electron microscopy (SEM) images of HCAT-2 (Figure 5 (left)) it can be seen that fiber-shaped nanoparticles of fibre width around $200 \mathrm{~nm}$ were

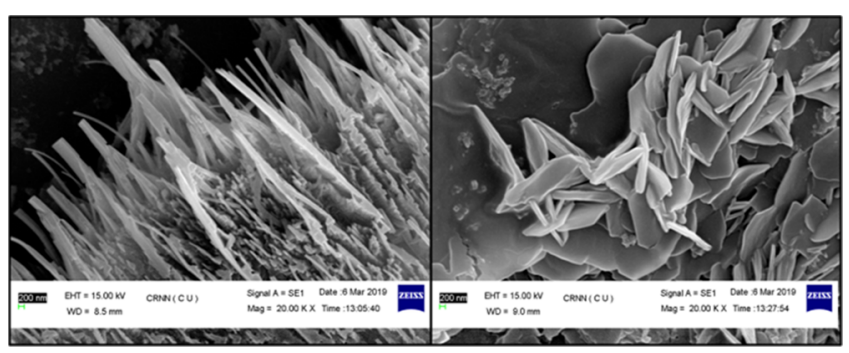

Figure 5. (Left) SEM image of HCAT-2 (right) and SEM image of CHCAT-2. formed. After coating with $\mathrm{CTAB}$, the nanosheet array of $\mathrm{CTAB} / \mathrm{Fe}_{3} \mathrm{O}_{4} @$ dopa@MnL is formed. ${ }^{27}$ It is important to note that the CTAB-coated magnetically separable nanoparticles CHCAT-1 and CHCAT-2 are well dispersed in aqueous solution, whereas the analogous uncoated nanoparticles are not stable in aqueous solution. Thus, CTAB plays an important role in the formation of stable assembled structures of magnetically separable nanoparticles making the system sufficiently hydrophilic.

The magnetic measurements of HCAT-1 and CHCAT-1 have been carried out at room temperature, and the results are displayed in (Figure S4a-d at the Supporting Information). It is evident from the recorded $M-H$ loop that both are ferromagnetic at this temperature. The magnetization of the prepared iron oxide was $61.376 \mathrm{emu} \mathrm{g}^{-1}$ and it decreased to a value of $44.574 \mathrm{emu}^{-1}$ after coating with dopamine. The magnetization value of $\mathrm{Fe}_{3} \mathrm{O}_{4} @$ dopa decreased further to a value of $37.5303 \mathrm{emu} \mathrm{g}^{-1}$ after the anchoring of complex 1. Finally, surfactant $\mathrm{CTAB}$-coated $\mathrm{CHCAT}-1$ generated a magnetization value of $25.425 \mathrm{emu}^{-1}$. The low magnetization value exhibited by CHCAT- 1 compared to the HCAT-1 one, $\mathrm{Fe}_{3} \mathrm{O}_{4}$ @dopa, $\mathrm{Fe}_{3} \mathrm{O}_{4}$ could be due to the contribution of the nonmagnetic surfactant moiety on the surface of HCAT-1. Despite the low magnetization value of the catalyst CTAB $/ \mathrm{Fe}_{3} \mathrm{O}_{4} @$ dopa@FeL, it is still sufficient for its efficient recovery from the reaction mixture with the help of an external magnet.

As already said, the two most efficient homogeneous catalysts, $\mathrm{FeL}^{1}$ and $\mathrm{MnL}^{1}$, were chosen for surface modification of our magnetic nanoparticles forming the newly synthesized CTABcoated heterogeneous catalysts CHCAT-1 and CHCAT-2. Unlike in the homogeneous case, with these catalysts, all the oxidations were performed in aqueous media. Taking $1 \mathrm{mmol}$ of benzyl alcohol as the test substrate, the catalyst concentration was varied between 80 and $120 \mathrm{mg}$. An increment of the catalyst concentration from 100 to $110 \mathrm{mg}$, resulted in an increase of the yield but further increase did not improve this yield. The time was varied between 3 and $7 \mathrm{~h}$. The optimum yield of products was obtained in $5 \mathrm{~h}$ and it did not enlarge even after $8 \mathrm{~h}$. As a consequence, a typical heterogeneous catalytic reaction consisted of alcohols ( $1 \mathrm{mmol}), \mathrm{H}_{2} \mathrm{O}_{2}(4 \mathrm{mmol})$, and CHCAT $(120 \mathrm{mg})$, with a continuous stirring for $6 \mathrm{~h}$. We have checked that CHCAT-1 and CHCAT-2 show significant catalytic activity for oxidation of a wide variety of alcohols to the corresponding aldehyde or ketone (Table 1).

To the best of our knowledge, this is the first time that a composite system of $\mathrm{CTAB} / \mathrm{Fe}_{3} \mathrm{O}_{4} @$ dopa@ML $(\mathrm{M}=\mathrm{Mn}$ or $\mathrm{Fe}$ ) was found to have an appreciable catalytic performance in oxidation of alcohols to aldehydes or ketones only in aqueous medium. Transfer of poorly aqueous soluble nanoparticles $\mathrm{Fe}_{3} \mathrm{O}_{4} @$ dopa@ML( $\mathrm{M}=\mathrm{Mn}$ or $\left.\mathrm{Fe}\right)$ to water media could be achieved thanks to the formation of an additional layer of the surfactant onto the nanoparticle surface in the so-called admicelles, the zeta potential studies confirmed this point. The admicelle motifs are a very crucial part of the entire catalytic system of CHCAT-1 and CHCAT-4, because they prevent the leaching of the potent metal ions from the catalyst surface as well as increase the solubility of nanocatalysts CHCAT-1 and CHCAT-2 (Figure S5).

The most probable mechanism of oxidation of alcohols by $\mathrm{H}_{2} \mathrm{O}_{2}$ in the presence of nanocatalysts CHCAT-1 and CHCAT2 involves two general steps. At first, the micelle structure will help the nanocatalysts to trap the organic molecules in the micelle core by dividing them into hundreds of small droplets 
Table 1. Oxidation of Alcohols by CHCAT-1 and CHCAT-2 ${ }^{a}$

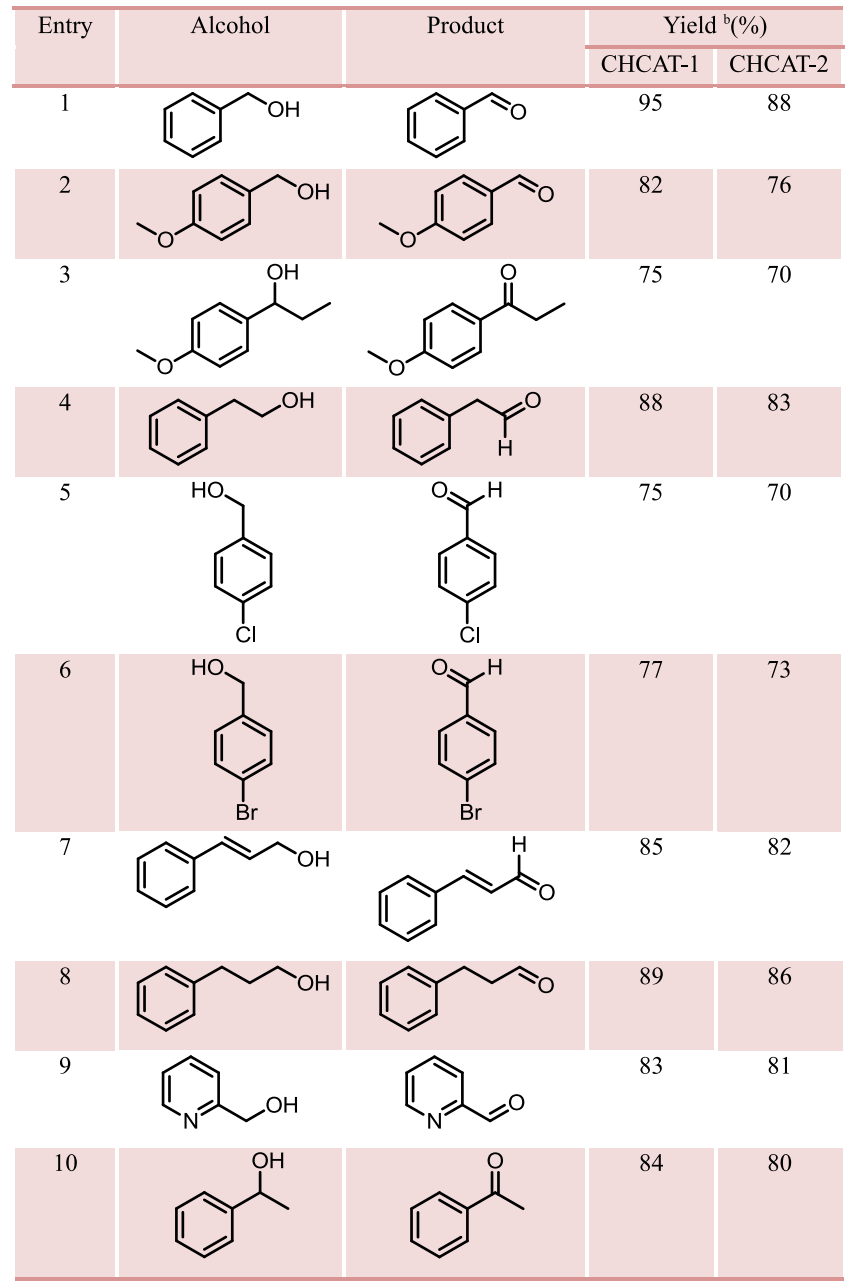

${ }^{a}$ Reaction conditions: $10 \mathrm{~mL}$ water, $1 \mathrm{mmol}$ alcohol, CHCAT- $1 / 2$ $(120 \mathrm{mg}), \mathrm{H}_{2} \mathrm{O}_{2}(4 \mathrm{mmol}) ; 6 \mathrm{~h}$ at room temperature under stirring. ${ }^{b}$ Isolated yield.

providing a large area of the contact surface of the organic starting materials with the active site of the catalysts in an aqueous solution. In the next step, the active site, that is, the metal centre of the catalyst, plays the crucial role. According to previous proposals, ${ }^{28,29}$ the reaction mechanism involves generation of a highly unstable metal-hydroperoxo species followed by an oxo-species. To obtain the evidence of $\mathrm{Fe}^{\mathrm{III}}-$ $\mathrm{OOH}$ and $\mathrm{Mn}^{\mathrm{III}}-\mathrm{OOH}$ intermediates that can possibly undergo $\mathrm{O}-\mathrm{O}$ bond cleavage to generate a high-valent iron oxo and manganese oxo species, respectively, we have focused our attention on trapping of $\left[\mathrm{Fe}^{\mathrm{III}} \mathrm{L}(\mathrm{OOH})\right]$ and $\left[\mathrm{Mn}^{\mathrm{III}} \mathrm{L}(\mathrm{OOH})\right]$ ( $\mathrm{L}=$ cyclohexane-1,2-diylbis (azanylylidene) bis(methanylylidene)bis(2,4-diXphenol)) after the addition of $\mathrm{H}_{2} \mathrm{O}_{2}$ to the corresponding catalyst.

The reaction of a methanolic solution of each iron complex 1-3 with 10 equiv of $\mathrm{H}_{2} \mathrm{O}_{2}$ led to the formation of a purple species that was characterized by UV-vis at $-20{ }^{\circ} \mathrm{C}$ as the corresponding hydroperoxo intermediate. The species comprising the $\mathrm{Fe}^{\mathrm{III}}-\mathrm{OOH}$ unit absorb around $550 \mathrm{~nm}$. We show the UV-visible spectra of complex $\mathbf{1}$ as a representative of the three iron ones and that of complex 4 for the $\mathrm{Mn}$ ones, all after the reaction with $\mathrm{H}_{2} \mathrm{O}_{2}$. In the first case, the reaction of a $\mathrm{CH}_{3} \mathrm{CN}$ solution of 1 with 10 equiv of $\mathrm{H}_{2} \mathrm{O}_{2}$ at $-20{ }^{\circ} \mathrm{C}$ led to the formation of a transient purple species characterized by a band at $546 \mathrm{~nm}$ (Figure S6 (left) at the Supporting Information). This band can be assigned to an LMCT between the hydroperoxo group and the Fe-III for $\mathrm{Fe}-\mathrm{OOH}$ entity. ${ }^{30,31}$ Attempts to isolate $\mathrm{L}^{1} \mathrm{Fe}^{\mathrm{III}}-\mathrm{OOH}$ species as the crystalline material was futile; hence, the intermediate $\mathrm{L}^{1} \mathrm{Fe}^{\mathrm{III}}-\mathrm{OOH}$ (Scheme 2) was characterized using various other techniques, including ESI-MS and DFT calculations.

Scheme 2. Schematic Representation of the Formation of Metal Hydroperoxo Species and Subsequent Conversion to Oxo Species

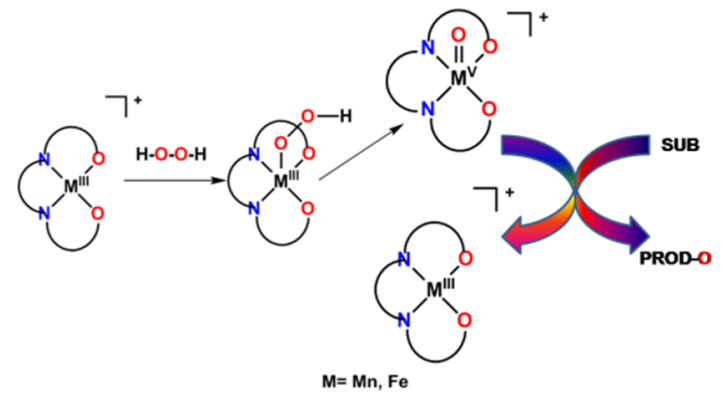

Similarly, in the case of 4 , that is, $\mathrm{MnL}^{1}$, addition of 10 equiv $\mathrm{H}_{2} \mathrm{O}_{2}$ in a $\mathrm{CH}_{3} \mathrm{CN}$ solution of $\mathrm{MnL}^{1}$ afforded a green intermediate $\mathrm{L}^{1} \mathrm{Mn}^{\mathrm{III}}-\mathrm{OOH}$ with absorption bands at 385 and $425 \mathrm{~nm}$, which is similar to that of the previously reported manganese(III) hydroperoxo complex. ${ }^{32}$ This intermediate species persisted for several hours at $25{ }^{\circ} \mathrm{C}$ (Figure S7 at the Supporting Information).

$\left[\mathrm{FeL}^{1}\right](\mathbf{1})$ and $\left[\mathrm{L}^{1} \mathrm{Fe}^{\mathrm{III}}(\mathrm{OOH})\right]$, as well as $\left[\mathrm{MnL}^{1}\right](4)$ and $\left[\mathrm{L}^{1} \mathrm{Mn}^{\mathrm{III}}-(\mathrm{OOH})\right]$, have been detected by ESI-MS. In all cases $\mathrm{CH}_{3} \mathrm{CN}$ was used as the solvent. A major peak at $m / z=513$. $9358 \mathrm{amu}$ has been found for $\mathbf{1}\left[\mathrm{C}_{20} \mathrm{H}_{16} \mathrm{Cl}_{4} \mathrm{FeN}_{2} \mathrm{O}_{2}\right]^{+}$(Figure S8 at the Supporting Information). After the addition of 10 equiv of $\mathrm{H}_{2} \mathrm{O}_{2}$ the ESI-MS spectrum (Figure S8 at the Supporting Information) exhibits a major peak at $m / z=685.4332 \mathrm{amu}$ which can be attributed to $\left[\mathrm{L}^{1} \mathrm{Fe}^{\mathrm{III}}(\mathrm{OOH})\right] \mathrm{K}^{+}$ $\left(\mathrm{C}_{20} \mathrm{H}_{17} \mathrm{Cl}_{4} \mathrm{FeN}_{2} \mathrm{O}_{4}\right) \mathrm{K}^{+}$. Peak at $m / z=657.0252 \mathrm{amu}$ can be attributed to the formation of $\left[\mathrm{L}^{1} \mathrm{Fe}^{\mathrm{V}}(\mathrm{O}) \mathrm{H}_{2} \mathrm{O}\right]^{+}$(Figure $\mathrm{S} 9$ at the Supporting Information).

Similarly, in the case of $\left[\mathrm{L}^{1} \mathrm{Mn}^{\mathrm{III}}-(\mathrm{OOH})\right]$, the ESI-spectrum of $\mathrm{MnL}^{1}$ (4) showed $\left[\mathrm{C}_{20} \mathrm{H}_{16} \mathrm{Cl}_{4} \mathrm{MnN}_{2} \mathrm{O}_{2}\right]^{+}$(Figure $\mathrm{S} 10$ at the Supporting Information). After addition of 10 equiv of $\mathrm{H}_{2} \mathrm{O}_{2}$ the ESI-MS spectrum (Figure S11 at the Supporting Information) exhibits a major peak at $m / z=545.9350 \mathrm{amu}$, which can be attributed to $\left[\mathrm{L}^{1} \mathrm{Mn}^{\mathrm{III}}(\mathrm{OOH})\right]^{+}\left(\mathrm{C}_{20} \mathrm{H}_{17} \mathrm{Cl}_{4} \mathrm{MnN}_{2} \mathrm{O}_{4}\right)^{+}$.

2.1. Theoretical Study on the Formation of Hydroperoxide MS Intermediates. It has been experimentally checked that Salen $\mathrm{Fe}$ (III) and $\mathrm{Mn}$ (III) complexes with $\mathrm{Cl}, \mathrm{Br}$, and I substituents at the ortho and para positions of both aromatic rings of the Schiff base ligand are able to oxidize different organic functionalities using $\mathrm{H}_{2} \mathrm{O}_{2}$ as the oxidant. Among them, those with $\mathrm{Cl}$ render better yields than those with $\mathrm{Br}$ and these better than I complexes. ${ }^{22}$ In the assumption that the size and electronic properties of the halogen affects the stability of the hydroperoxo intermediates formed in the initial reaction stages, it is useful to theoretically characterize these complexes and compute their energy. However, it is not meaningful to compare the absolute energy of chemical compounds made of different numbers or types of atoms, so we have calculated the Gibbs energy associated with a common 
process in which each an initial metal complex reacts with $\mathrm{OOH}^{-}$to render the corresponding hydroperoxo intermediate, as schematically depicted in eq 1.

$$
\begin{aligned}
& {[\mathrm{Fe}(\mathrm{III}) / \mathrm{Mn}(\mathrm{III}) \mathrm{eX} 4]^{+}+\mathrm{OOH}^{-}} \\
& \quad \rightarrow\left[\mathrm{Fe}(\mathrm{III}) / \mathrm{Mn}(\mathrm{III})-\mathrm{OOH}^{-} \mathrm{X} 4\right]
\end{aligned}
$$

Two spin multiplicities are possible for the $\mathrm{Fe}(\mathrm{III})$ and $\mathrm{Mn}$ (III) complexes, a low one with $2 S+1=2$, 3, for Fe(III) and $\mathrm{Mn}$ (III), respectively, and a high one with $2 S+1=6,5$, for $\mathrm{Fe}(\mathrm{III})$ and $\mathrm{Mn}$ (III), respectively. Figures S12-S15 collects the optimized geometry of initial and hydroperoxo $\mathrm{Fe}$ (III) and $\mathrm{Mn}$ (III) complexes, with high and low spin, in acetonitrile solution. At the high spin, in Fe(III) hydroperoxide complexes the Schiff base acquires a dome shape making all bonds between the metal and its coordinated atoms longer than in the initial complexes. However, the distance between ortho halogens reduces in hydroperoxide intermediates. Unlike for $\mathrm{Mn}$ (III) high spin complexes, ortho halogens become further apart in the hydroperoxo species than in the initial ones. At low spin, initial $\mathrm{Fe}$ (III) complexes present a much more symmetric coordination around the metal with bond distances shorter than in the corresponding high spin counterparts. At both $\mathrm{Fe}$ (III) and $\mathrm{Mn}$ (III) low spin Fe(III) hydroxo complexes, ortho halogens become further apart than in the initial ones. Table S7 shows the absolute electronic and Gibbs energies of all these complexes with both spin multiplicities, whereas Table 2 displays the

Table 2. B3LYP/6-31+G(d,p) (LANL2DZ for Fe(III)/

$\mathrm{Mn}(\mathrm{III}), \mathrm{Cl}, \mathrm{Br}$, and I) relative Electronic, $\Delta E_{\mathrm{e}}$, and Gibbs, $\Delta G_{\text {sol }}$, Energies for the Reaction Where Fe(III)/Mn(III) complexes (with $\mathrm{Cl}, \mathrm{Br}$, or I Substituents) Link to the $\mathrm{OOH}-$ Group

$\begin{array}{ccc}\text { complexes } & \Delta E_{\mathrm{e}}(\mathrm{kcal} / \mathrm{mol}) \mathrm{Fe} / \mathrm{Mn} & \Delta G_{\text {sol }}(\mathrm{kcal} / \mathrm{mol}) \mathrm{Fe} / \mathrm{Mn} \\ \mathrm{X}=\mathrm{Cl} & -48.5 /-31.2 & -37.1 /-20.4 \\ \mathrm{X}=\mathrm{Br} & -48.0 /-30.9 & -35.7 /-20.1 \\ \mathrm{X}=\mathrm{I} & -47.2 /-30.4 & -36.1 /-19.5\end{array}$

relative electronic and Gibbs energies corresponding to the reactions compactly displayed in eq 1 (calculated as the summation of the energy of the corresponding product menus summation of the energy of the corresponding reactants in eq 1). Data in Table S7 confirms that high spin complexes are more stable than the corresponding low spin ones in all cases, so high spin species have been considered as those involved in our process of interest.

In terms of both electronic and Gibbs energies in acetonitrile solution, all the hydroperoxide products are more stable than the initial reactants, that is, the six reactions are exergonic at the conditions considered in the calculation. Fe(III) complexes render much more stable hydroperoxo intermediates than the $\mathrm{Mn}$ (III) ones. Both electronic and Gibbs energies agree to show that the stabilization of $\mathrm{OOH}$ complexes slightly increases from chlorine to bromine and iodine complexes, in agreement with the experimental largest activity of $\mathrm{Cl}$ catalysts. Geometries collected in Figures S12-S15 for the high spin complexes involved in the studied processes show how the $\mathrm{OOH}$ group bonds closely to $\mathrm{Fe}$ (III) and $\mathrm{Mn}$ (III). The increasing volume occupied by $\mathrm{Cl}, \mathrm{Br}$, and I substituents slightly affects the relative position of both phenyl rings as well as the repulsive interaction among the halogen groups. Obviously, the larger the halogen, the larger this repulsion, as computationally probed.

Because complex 1, that is, $\mathrm{FeL}^{1}$ among the series of iron complexes and complex 4, that is, $\mathrm{MnL}^{1} \mathrm{Cl}$ among the series of manganese ones, were the most efficient in generating iron and manganese hydroperoxo species, respectively, henceforth these two complexes were selected for surface modification and further study regarding heterogeneous catalysis was performed with them (Scheme 1).

\section{CONCLUSIONS}

This present study deals with a green and sustainable synthetic route for the oxidation of alcohols using magnetically separable nanocatalysts. To be able to work in an aqueous medium and to avoid metal particle lixiviation, we have successfully designed and synthesized $\mathrm{CTAB}$-coated $\mathrm{Fe}_{3} \mathrm{O}_{4}$ nanoparticles supporting
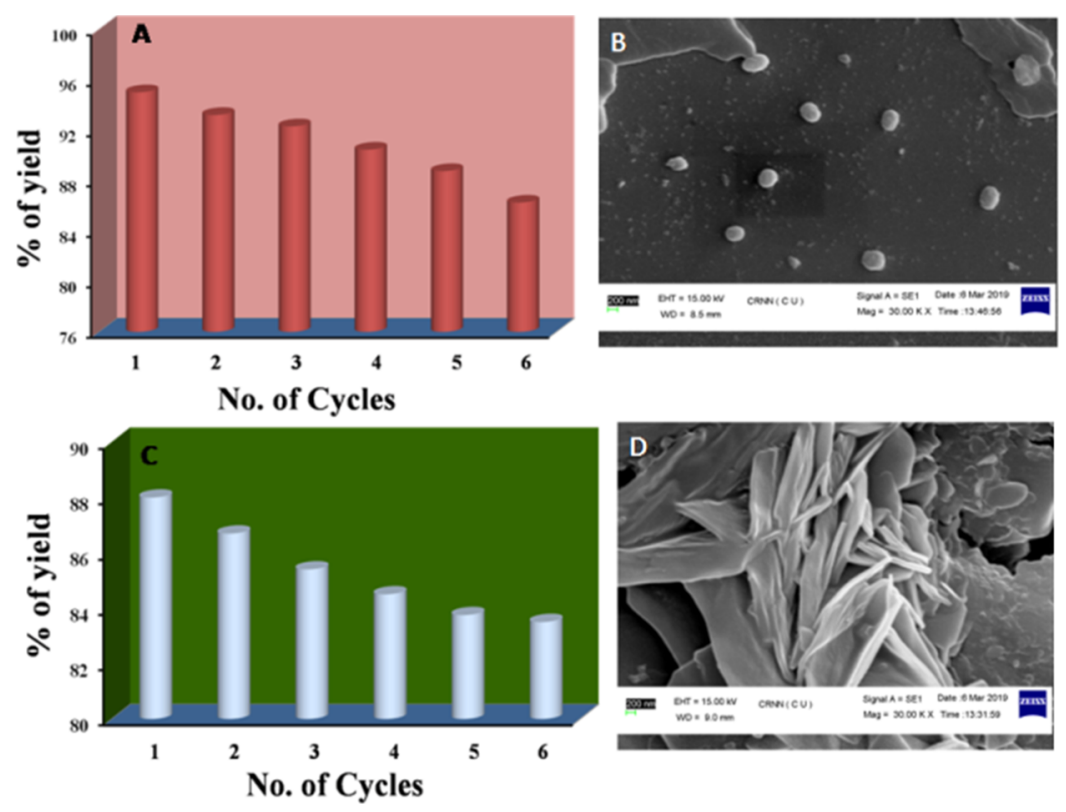

Figure 6. Reusability graphs of CHCAT-1 and CHCAT-2 (A,C); SEM image of reused CHCAT-1 and CHCAT-2 after the sixth cycle (B,D). 
iron and manganese complexes previously confirmed as good homogeneous catalysts. The magnetic character of the nanoparticles was not compromised with the coating of the CTAB surfactant and, as a result, these catalysts could be reused upto 6 oxidation cycles without any appreciable loss in their catalytic activity (Figure 6). Actually, they have been successfully used for the oxidation of a range of alcohols in an aqueous medium at room temperature. The present approach of nanomaterial synthesis and catalytic oxidation could serve as a greener alternative to the conventional oxidation methods that involve toxic metal catalysts.

\section{EXPERIMENTAL SECTION}

4.1. Materials and Methods. All chemicals were obtained from commercial sources and used as received. Solvents were dried according to standard procedures and distilled prior to use.

Elemental analyses (carbon, hydrogen, and nitrogen) were performed using a PerkinElmer 240C elemental analyzer. Infrared spectra $\left(4000-500 \mathrm{~cm}^{-1}\right)$ were recorded at $27{ }^{\circ} \mathrm{C}$ using a PerkinElmer RXI FT-IR spectrophotometer with $\mathrm{KBr}$ pellets. Electronic spectra $(800-200 \mathrm{~nm})$ were obtained at 27 ${ }^{\circ} \mathrm{C}$ using a Shimadzu UV-3101PC with acetonitrile as the solvent and reference. Thermal analyses (TG-DTA) were carried out on a Mettler Toledo (TGA/SDTA851) thermal analyzer in flowing dinitrogen (flow rate: $30 \mathrm{~cm}^{3} \mathrm{~min}^{-1}$ ). Conductance of the methanolic solution of complexes was measured using a SYSTRONICS 306 conductivity meter. SEM measurements were carried out with a JEOL JSM-6700F fieldemission microscope. X-ray powder diffraction was performed on a X'Pert-PRO diffractometer monochromated $\mathrm{Cu} \mathrm{K} \alpha$ radiation $(40.0 \mathrm{kV}, 30.0 \mathrm{~mA})$ at room temperature. A vibrating sample magnetometer (EV-9, Microsense, ADE) was utilized for obtaining the magnetization curves. Electrospray mass spectra have been recorded on a WATERS Xevo G2-S QTof mass spectrometer using high resolution mass spectrometry grade acetonitrile as the solvent. The hydrodynamic diameters and $\zeta$ potential of the gold nanoarchitectures were measured using a Zetasizer Nano ZS90 (Malvern Instruments).

$\mathrm{Fe}_{3} \mathrm{O}_{4}$ and $\mathrm{Fe}_{3} \mathrm{O}_{4} @$ dopa nanoparticles were synthesized using methods previously reported. ${ }^{20-23} \mathrm{Fe}_{3} \mathrm{O}_{4} @$ dopa@FeL (HCAT-1) and $\mathrm{Fe}_{3} \mathrm{O}_{4} @$ dopa@MnL (HCAT-2) were also synthesized following earlier methods. ${ }^{20-23}$ CTAB-coated nanoparticles CHCAT-1 (CTAB/ $\mathrm{Fe}_{3} \mathrm{O}_{4} @$ dopa@FeL) and CHCAT-2 (CTAB/ $/ \mathrm{Fe}_{3} \mathrm{O}_{4} @$ dopa@MnL) were prepared using the following procedure. An aqueous solution of the cationic surfactant $\mathrm{CTAB}$ was initially prepared (conc of $\mathrm{CTAB}=0.89 \times$ $\left.10^{-3} \mathrm{~mol} \mathrm{~L}^{-1}\right)$. HCAT-1 (1.2 g) and HCAT-2 (1.2 g) were added separately to a $25 \mathrm{~mL}$ of the surfactant dissolved in water and the final mixtures were rigorously stirred for $36 \mathrm{~h}$ at room temperature and hence the dispersion obtained was centrifuged for $5 \mathrm{~min}$ at $11000 \mathrm{rpm}$. The supernatant solution was discarded and the sediment was washed twice with doubly distilled water followed by further washing with acetone followed by drying overnight at room temperature (Scheme 1). The two final coated solid samples namely CHCAT- 1 and CHCAT- 2 were then further characterized.

\section{ASSOCIATED CONTENT}

\section{S Supporting Information}

The Supporting Information is available free of charge on the ACS Publications website at DOI: 10.1021/acsomega.9b01143.
Synthesis of homogeneous catalysts, X-ray crystal structure description, FT-IR, PXRD, and magnetization curves of the heterogeneous catalysts, UV-visible and ESI-MS spectrum for the generation of hydroperoxo species, and DFT optimization figures (CIF)

(PDF)

\section{AUTHOR INFORMATION}

\section{Corresponding Authors}

*E-mail: isabel@uniovi.es (M.I.M.).

*E-mail: tanmayc2003@gmail.com (T.C.).

\section{ORCID}

Maria Isabel Menendez: 0000-0002-5062-4319

Tanmay Chattopadhyay: 0000-0003-0245-5116

\section{Notes}

The authors declare no competing financial interest.

\section{ACKNOWLEDGMENTS}

A.C. thanks University Research Fellowship for financial support. T.C. is thankful to UGC, India for providing fellowship [ref. no: 21/06/2015(I) EU-V]. Financial support by the Department of Higher Education, Science \& Technology and Biotechnology, Government of West Bengal [memo no. 21 (Sanc.)/ST/P/S\&T/15G-16/2017 dt. 12-06-2018] is gratefully acknowledged by T.C. The authors wish to thank the University of Calcutta for providing the facility of the field emission SEM, high-resolution transmission electron microscopy, PXRD, and FT-IR by the DST FIST program. M.I.M. thanks Ministerio de Economía y Competitividad of Spain (grant no. CTQ2015-70231-P) for financial support.

\section{REFERENCES}

(1) Modern Oxidation Methods, 2nd ed.; Bäckvall, J.-E., Ed.; WileyVCH: Weinheim, 2010.

(2) Piera, J.; Bäckvall, J.-E. Catalytic Oxidation of Organic Substrates by Molecular Oxygen and Hydrogen Peroxide by Multistep Electron Transfer-A Biomimetic Approach. Angew. Chem., Int. Ed. 2008, 47, 3506-3523.

(3) Ley, S. V. Comprehensive Organic Synthesis: Oxidation, 1st ed.; Trost, B. M., Fleming, I., Eds.; Pergamon-Elsevier Ltd.: Oxford, UK, 2007; Vol. 2.

(4) Liquid Phase Aerobic Oxidation Catalysis: Industrial Applications and Academic Perspectives; Stahl, S. S., Alsters, P. L., Eds.; Wiley-VCH Verlag GmbH \& Co. KGaA: Weinhein, 2016.

(5) Transition Metal Catalysis in Aerobic Alcohol Oxidation; Cardona, F., Parmeggiani, C., Eds.; RSC Green Chemistry No. 28; Royal Society of Chemistry: Cambridge, UK, 2015.

(6) Liu, C.; Liu, D.; Lei, A. Recent advances of transition-metal catalyzed radical oxidative cross-couplings. Acc. Chem. Res. 2014, 47, $3459-3470$.

(7) Shi, Z.; Zhang, C.; Tang, C.; Jiao, N. Recent advances in transitionmetal catalyzed reactions using molecular oxygen as the oxidant. Chem. Soc. Rev. 2012, 41, 3381-3430.

(8) Shinoda, S.; Kojima, T.; Saito, Y. $\mathrm{Rh}_{2}(\mathrm{OAc})_{4}-\mathrm{PPh}_{3}$ as a catalyst for the liquid-phase dehydrogenation of 2-propanol. J. Mol. Catal. 1983, 18, 99-104.

(9) Zhang, J.; Gandelman, M.; Shimon, L. J. W.; Rozenberg, H.; Milstein, D. Electron-Rich, Bulky Ruthenium PNP-Type Complexes. Acceptorless Catalytic Alcohol Dehydrogenation. Organometallics 2004, 23, 4026-4033. 
(10) Fujita, K.-i.; Yoshida, T.; Imori, Y.; Yamaguchi, R. Dehydrogenative Oxidation of Primary and Secondary Alcohols Catalyzed by a Cp*Ir Complex Having a Functional C,N-Chelate Ligand. Org. Lett. 2011, 13, 2278-2281.

(11) Mitsudome, T.; Mikami, Y.; Funai, H.; Mizugaki, T.; Jitsukawa, K.; Kaneda, K. Oxidant-Free Alcohol Dehydrogenation Using a Reusable Hydrotalcite-Supported Silver Nanoparticle Catalyst. Angew. Chem. 2008, 120, 144-147.

(12) Feng, B.; Chen, C.; Yang, H.; Zhao, X.; Hua, L.; Yu, Y.; Cao, T.; Shi, Y.; Hou, Z. Ionic Liquid-Promoted Oxidant-Free Dehydrogenation of Alcohols with Water-Soluble Ruthenium Nanoparticles in Aqueous Phase. Adv. Synth. Catal. 2012, 354, 1559-1565.

(13) Polshettiwar, V.; Baruwati, B.; Varma, R. S. Magnetic Nanoparticle-Supported Glutathione: A Conceptually Sustainable Organocatalyst. Chem. Commun. 2009, 1837-1839.

(14) Baig, R. B. N.; Leazer, J.; Varma, R. S. Magnetically Separable $\mathrm{Fe}_{3} \mathrm{O}_{4} @$ DOPA-Pd: A Heterogeneous Catalyst for Aqueous Heck Reaction. Clean Technol. Environ. Policy 2015, 17, 2073-2077.

(15) Gawande, M. B.; Branco, P. S.; Varma, R. S. Nano-Magnetite $\left(\mathrm{Fe}_{3} \mathrm{O}_{4}\right)$ as Support for Recyclable Catalysts in the Development of Sustainable Methodologies. Chem. Soc. Rev. 2013, 42, 3371-3393.

(16) Yao, L.; Zhao, J.; Lee, J.-M. Small Size Rh Nanoparticles in Micelle Nanostructure by Ionic Liquid/CTAB for Acceptorless Dehydrogenation of Alcohols Only in Pure Water. ACS Sustainable Chem. Eng. 2017, 5, 2056-2060.

(17) Yao, L.; Liu, C.; Chong, W. H.; Wang, H.; Chen, L.; Chen, H. Understanding the phase emergence of mesoporous silica. Small 2015, 11, 232-238.

(18) Chakraborty, T.; Chakraborty, A.; Maity, S.; Das, D.; Chattopadhyay, T. Conglomerated system of $\mathrm{Ag}$ nanoparticles decorated $\mathrm{Al}_{2} \mathrm{O}_{3}$ supported cobalt and copper complexes with enhanced catalytic activity for oxidation reactions. Mol. Catal. 2019, 462, 104-113.

(19) Nam, W.; Ho, R.; Valentine, J. S. Iron-cyclam complexes as catalysts for the epoxidation of olefins by $30 \%$ aqueous hydrogen peroxide in acetonitrile and methanol. J. Am. Chem. Soc. 1991, 113, $7052-7054$

(20) Chakraborty, A.; Dasgupta, S.; Chatterjee, S.; Menéndez, M. I.; Das, D.; Chattopadhyay, T. Oxidation of Organic Functionalities by $\mathrm{PhI}(\mathrm{OAc})_{2}$ Catalysed by Magnetically Separable $\mathrm{Fe}_{3} \mathrm{O}_{4} @$ dopaSupported $\mathrm{Mn}$ (III) Complexes: Combined Experimental and Theoretical Approach. ChemistrySelect 2017, 2, 8686-8700.

(21) Chattopadhyay, T.; Chakraborty, A.; Dasgupta, S.; Dutta, A.; Menéndez, M. I.; Zangrando, E. A route to magnetically separable nanocatalysts: Combined experimental and theoretical investigation of alkyl substituent role in ligand backbone towards epoxidation ability. Appl. Organomet. Chem. 2017, 31, No. e3663.

(22) Chakraborty, A.; Chattopadhyay, T. $\mathrm{Fe}_{3} \mathrm{O}_{4} @$ dopa (dopa = dopamine hydrochloride) functionalized $\mathrm{Mn}$ (III) Schiff base complex: A promising magnetically separable heterogeneous catalyst for oxidative transformations. J. Coord. Chem. 2017, 70, 3293-3307.

(23) Adhikary, J.; Datta, A.; Dasgupta, S.; Chakraborty, A.; Menéndez, M. I.; Chattopadhyay, T. Development of an efficient magnetically separable nanocatalyst: theoretical approach on the role of the ligand backbone on epoxidation capability. RSC Adv. 2015, 5, 92634-92647.

(24) Yang, Y.; Kimura, K. Surface charge driven size evolution during the formation of self-assembled nanostructures from discrete hydrophilic silver nanoparticles. Nanotechnology 2007, 18, 465603.

(25) Wan, J.; Tang, G.; Qian, Y. Room Temperature Synthesis of Single-Crystal Fe3O4 Nanoparticles with Superparamagnetic Property. Appl. Phys. A: Mater. Sci. Process. 2007, 86, 261-264.

(26) Filippousi, M.; Angelakeris, M.; Katsikini, M.; Paloura, E.; Efthimiopoulos, I.; Wang, Y.; Zamboulis, D.; Van Tendeloo, G. Surfactant Effects on the Structural and Magnetic Properties of Iron Oxide Nanoparticles. J. Phys. Chem. C 2014, 118, 16209-16217.

(27) Alimirsalari, S.; Tajabadi, F.; Salehkoutahi, S. M.; Ghahary, R.; Taghavinia, N. Nanosheet arrays of $\mathrm{TiO}_{2}$ synthesized by one step conversion of $\mathrm{ZnO}$ nanosheets: boosting of electron transport rate and application in dye solar cells. RSC $A d v$. 2014, 4, 45174-45179.
(28) Li, F.; Meier, K. K.; Cranswick, M. A.; Chakrabarti, M.; Van Heuvelen, K. M.; Münck, E.; Que, L., Jr. Characterization of a HighSpin Non-Heme FeIII-OOH Intermediate and Its Quantitative Conversion to an FeIV=O Complex. J. Am. Chem. Soc. 2011, 133, $7256-7259$.

(29) Sankaralingam, M.; Lee, Y.-M.; Jeon, S. H.; Seo, M. S.; Cho, K.B.; Nam, W. A mononuclear manganese(iii)-hydroperoxo complex: synthesis by activating dioxygen and reactivity in electrophilic and nucleophilic reactions. Chem. Commun. 2018, 54, 1209-1212.

(30) Girerd, J. J.; Banse, F.; Simaan, A. J. Metal-Oxo and Metal-Peroxo Species in Catalytic Oxidations; Meunier, B.; Springer: Berlin, 2000; Vol. 97, pp 145-177.

(31) Solomon, E. I.; Brunold, T. C.; Davis, M. I.; Kemsley, J. N.; Lee, S.-K.; Lehnert, N.; Neese, F.; Skulan, A. J.; Yang, Y.-S.; Zhou, J. Geometric and Electronic Structure/Function Correlations in NonHeme Iron Enzymes. Chem. Rev. 2000, 100, 235-350.

(32) Sankaralingam, M.; Lee, Y.-M.; Jeon, S. H.; Seo, M. S.; Cho, K.B.; Nam, W. A mononuclear manganese(III)-hydroperoxo complex: synthesis by activating dioxygen and reactivity in electrophilic and nucleophilic reactions. Chem. Commun. 2018, 54, 1209-1212. 